Board of Governors of the Federal Reserve System

International Finance Discussion Papers

Number 568

October 1996

\title{
HAZARDS IN IMPLEMENTING A MONETARY CONDITIONS INDEX
}

Kari H. Eika, Neil R. Ericsson, and Ragnar Nymoen

NOTE: International Finance Discussion Papers are preliminary materials circulated to stimulate discussion and critical comment. References in publications to International Finance Discussion Papers (other than an acknowledgment that the writer has had access to unpublished material) should be cleared with the author or authors. 


\begin{abstract}
Some recent studies have suggested constructing a Monetary Conditions Index (or MCI) to serve as an indicator of monetary policy stance. The central banks of Canada, Sweden, and Norway all construct an MCI and (to varying degrees) use it in conducting monetary policy. Empirically, an MCI is calculated as the weighted sum of changes in a short-term interest rate and the exchange rate relative to values in a baseline year. The weights aim to reflect these variables' effects on longer-term focuses of policy - economic activity and inflation. This paper derives analytical and empirical properties of MCIs in an attempt to ascertain their usefulness in monetary policy.

An MCI assumes an underlying model relating economic activity and inflation to the variables in the MCI. Several issues arise for that model, including its empirical constancy, cointegration, exogeneity, dynamics, and potential omitted variables. Because of its structure, the model is unlikely to be constant or to have strongly exogenous variables; and we show that constancy and exogeneity are critical for the usefulness of an MCI. Empirical analyses of Canadian, Swedish, and Norwegian MCIs confirm such difficulties. Thus, the value of an MCI for conduct of economic policy is in doubt.
\end{abstract}

Keywords: constancy, cointegration, dynamic specification, exogeneity, inflation, MCI, monetary conditions index, monetary policy, output, prices. 


\title{
Hazards in Implementing a Monetary Conditions Index
}

\author{
Kari H. Eika, Neil R. Ericsson, and Ragnar Nymoen*
}

\section{Introduction}

In recent years, the focus of monetary policy in many countries has shifted from intermediate targets such as monetary growth rates to more final policy targets such as macroeconomic stability and growth; cf. Leiderman and Svensson (1995). This change in focus has increased interest in quantifying the effects of policy instruments on output and inflation, and in using such estimates in the conduct of monetary policy. The Bank of Canada has proposed a univariate measure of the effects of the real interest rate level and the real exchange rate on economic activity and inflation - a "Monetary Conditions Index" or MCI; see Freedman (1994). The index is a weighted sum of changes in a short-term interest rate and the exchange rate relative to values in a baseline year, with the weights reflecting these variables' estimated relative effects on the longer-term target variable, e.g., output or inflation.

\footnotetext{
*Forthcoming in a special issue of the Oxford Bulletin of Economics and Statistics entitled The Econometrics of Economic Policy, Anindya Banerjee and David F. Hendry (eds.), Vol. 58, No. 4, November 1996. The first two authors are staff economists in the Research Department, Norges Bank, Oslo, Norway, and the Division of International Finance, Federal Reserve Board, Washington, D.C., U.S.A., respectively. The third author is an associate professor of economics at the University of Oslo and a staff economist in the Research Department of Norges Bank. The authors may be reached on the Internet at kari.eika@norges-bank.no, ericsson@frb.gov, and ragnar.nymoen@econ.uio.no respectively. The views expressed in this paper are solely the responsibility of the authors and should not be interpreted as reflecting those of Norges Bank, the Board of Governors of the Federal Reserve System, or other members of their staffs. The second author gratefully acknowledges the generous hospitality of Norges Bank, where he was visiting when he became involved in this research. An earlier version of this paper appeared under the title "Making a Monetary Conditions Index Operational". We wish to thank Anindya Banerjee, Carol Bertaut, Richard Dennis, Pierre Duguay, Dick Freeman, Dale Henderson, David Hendry, Eilev Jansen, Karen Johnson, Anne Sofie Jore, David Longworth, Cathy Mann, Arturo O'Connell, Adrian Pagan, Sunil Sharma, Ralph Smith, an anonymous referee, and participants at the Project LINK Fall 1995 meeting and the EUI conference "The Econometrics of Economic Policy" for helpful discussions and comments; Bengt Hansson and Anne Sofie Jore for providing the data in Hansson (1993) and Jore (1994); and Jurgen Doornik and David Hendry for providing us with a $\beta$-test version of PcGive 9.00. All numerical results were obtained using PcGive Professional Versions 8.00, 8.10, and 9.00 $\beta 01$; cf. Doornik and Hendry (1994). This paper is being simultaneously circulated as Working Paper (Arbeidsnotat) No. 1996/9 by the Research Department of Norges Bank, Memorandum No. 32 (October 1996) by the Department of Economics at the University of Oslo, and International Finance Discussion Paper No. 568 by the Board of Governors of the Federal Reserve System.
} 
MCIs are now calculated by a number of central banks and policy organizations. The Bank of Canada (1995, p. 14) interprets changes in its MCI as measuring "the degree of tightening or easing in monetary conditions". Further, it uses its MCI as the operational target for monetary policy, generalizing on earlier use of the interest rate alone. For small open economies, focusing on the exchange rate as well as the interest rate seems particularly important in policy making because the exchange rate may be a primary channel through which monetary policy affects output and prices. In line with this concern, the central banks of Sweden and Norway include an MCI as an indicator of monetary policy stance in their inflation reports. The International Monetary Fund constructs and uses MCIs in its policy evaluation of individual countries, with some of those MCIs being reported in its World Economic Outlook; see the International Monetary Fund (1996, p. 16). Discussion of MCIs has also expanded from policy circles to the business arena, as the following two examples illustrate. In a recent front-page editorial of the Financial Times, Chote (1996) discusses IMF policy recommendations for Germany with an accompanying chart showing MCIs for the four main EU economies. Davies and Simpson (1996) and Suttle (1996), in widely circulated publications of Goldman Sachs and JP Morgan, discuss MCIs for numerous countries.

Although MCIs have become a widely used indicator of monetary conditions, little has been done to investigate their conceptual and empirical foundations. For example, the weights for an MCI are not directly observable, but are derived from an empirical model of the economy. Hence an operational MCI is model dependent. Both analytically and empirically, that model makes strong assumptions about parameter constancy, cointegration, dynamics, exogeneity, and the choice of variables. These assumptions are all testable in practice, but few such tests have been calculated for current MCI models. If the model has (e.g.) unstable parameters or unwarranted exogeneity assumptions, an MCI could be highly misleading for policy, so the lack of testing is worrying. Thus, to ascertain the usefulness of MCIs in monetary policy, this paper derives analytical and empirical properties of MCIs from the properties of the models on which they are based. Our results cast serious doubt on the practical value of an MCI in conducting economic policy.

This paper is organized as follows. Section 2 defines and motivates the MCI. Section 3 evaluates its analytical properties in the context of a simple dynamic model, with key issues for an operational MCI being dynamics, data nonstationarity, exogeneity, parameter constancy, and omitted variables. Section 4 reconsiders these issues for the empirical implementations of Canadian, Swedish, and Norwegian MCIs. Section 5 concludes. Appendix A presents details on the estimation of the Swedish model, and Appendix B describes the data for the Swedish and Norwegian models. 


\section{The MCI Defined}

This section defines the MCI and summarizes its role in monetary policy. Implementing an MCI requires clarifications in the monetary policy goals and assumptions about functional specification, so these issues are briefly discussed.

The Monetary Conditions Index at time $t$ [denoted $\left.M C I(v)_{t}\right]$ is a weighted sum of changes in an exchange rate $(e)$ and an interest rate $(R)$ from their levels in a chosen base year $(t=0)$ :

$$
M C I(v)_{t}=\theta_{v, e}\left(e_{t}-e_{0}\right)+\theta_{v, R}\left(R_{t}-R_{0}\right) .
$$

Thus, the calculated MCI depends upon the weights $\theta_{v, e}$ and $\theta_{v, R}$, the measures of the exchange rate and the interest rate, and the choice of base year. The weights are the parameters of interest in constructing the MCI, and those weights are chosen to reflect the effects that changes in the monetary instruments have on the target variable $v$. Any given pair of weights reflects the choice of $v$, which typically is either output $(Y)$ or inflation $(\Delta p)$. Levels of variables are denoted by upper case, their logarithms by lower case, and $\Delta$ is the first difference operator (e.g., $\Delta p_{t}$ is $p_{t}-p_{t-1}$, which is the inflation rate). Usually, the exchange rate in (1) is in logarithms or in percent deviations from its baseline value, whereas the interest rate is in levels. In practice, the exchange rate and the interest rate in (1) could be either real (as in Hansson and Lindberg (1994)) or nominal (as in the Bank of Canada (1994)). Over short periods, MCIs computed from real and nominal rates often move similarly because relative prices and the inflation rate are reasonably constant. The weights themselves typically derive from models involving real variables. In much of the analytical discussion below, real rates are assumed for both the estimation of the weights and the calculation of the MCI, although the issues raised apply equally to MCIs using nominal rates.

In implementing an MCI in monetary policy, the central bank adjusts its instrument (e.g., the discount rate) to achieve desired outcomes of its operational target. Here, the operational target is the MCI, which generalizes on the historical use of the interest rate or the exchange rate alone. The variable(s) entering the operational target then affect outcomes of the ultimate target $v$. The weights in (1) are meant to reflect the linkage between the operational target and $v$, with changes in the MCI indicating likely changes in $v$. For expositional convenience below, $e$ and/or $R$ are treated as policy instruments, thereby assuming a direct and unequivocal relationship between the actual instruments and the operational target. In practice, $e$ and $R$ are operational targets, with variables such as the discount rate being the actual policy instruments. This distinction between operational targets and policy instruments in- 
troduces an additional link in the monetary transmission mechanism, through which non-policy variables might affect $e$ and $R$. For a clear, detailed discussion of this framework of monetary policy and the associated terminology, see Freedman (1994).

The above description is somewhat idealized, and the actual use of MCIs varies across the institutions that publish them. A detailed account of the role of MCIs in the formulation of monetary policy is beyond the scope of this paper. However, as emphasized by Freedman (1994, p. 465), an MCI is not used mechanically, but is cross-checked against other types of information and is subject to judgment by senior management.

Instead of focusing on the heterogeneity inherent in practical monetary policy conduct, this paper concentrates on a property shared by all MCIs - the MCI weights $\theta_{v, e}$ and $\theta_{v, R}$ are unknown to policy makers and need to be estimated. Starting from this property, MCIs, like any other model-based measure of economic performance, can be assessed with the aid of econometric concepts and techniques. While considerable ingenuity has gone into incorporating MCIs into operational monetary policy, little existing work clarifies and tests the underlying econometric assumptions. This paper aims to help rectify that shortcoming.

As a preliminary, we note that care must be taken when choosing the weights in (1). For instance, consider the very simple example where a linear static framework is appropriate. The weights $\theta_{v, e}$ and $\theta_{v, R}$ are then the two partial derivatives of the target variable $v$ with respect to the exchange rate and the interest rate:

$$
\theta_{v, e}=\frac{\partial v}{\partial e} \text { and } \theta_{v, R}=\frac{\partial v}{\partial R} .
$$

Linearity may be a poor assumption for obtaining a relationship between (e.g.) the level of GDP and the exchange rate and the interest rate, so the data are often transformed (as here) with the target variable and the exchange rate in logarithms. The derivative $\partial v / \partial e$ is then an elasticity and $\partial v / \partial R$ is a semi-elasticity, as in Hansson (1993) and Jore (1994). Below, we use the broad term multiplier for $\partial v / \partial e$ and $\partial v / \partial R$, bearing in mind that their exact interpretation hinges on the underlying transformations of the raw variables.

Relatedly, the weights $\theta_{v, e}$ and $\theta_{v, R}$ are affected by scaling the target variable by another variable. For instance, if $v$ is GDP, the weights depend upon whether the target is GDP itself, GDP relative to capacity, or GDP growth (current GDP scaled by its lagged value). 


\section{Econometric Issues and Assumptions}

This section identifies and discusses five critical econometric issues that arise in making an MCI operational: dynamics (Section 3.1), data nonstationarity (Section 3.2), exogeneity (Section 3.3), parameter constancy (Section 3.4), and omitted variables (Section 3.5). For each issue, the empirical model underlying the MCI contains various assumptions, which a stylized model helps convey. These assumptions are often testable and, if violated, directly affect the economic interpretation of the MCI. While each issue is discussed in a separate subsection, connections between the issues are multiple and are identified insofar as is practical. Section 3.6 considers difficulties in using an MCI even if those assumptions are satisfied.

First, dynamics in the relationship between $v$ and $e$ and $R$ generally imply different short-, medium-, and long-run multipliers. The choice of the weights $\theta_{v, e}$ and $\theta_{v, R}$ thus depends upon the time horizon of interest. Second, the temporal properties of the data themselves bear on the construction of an MCI. In particular, nonstationarity of the data (e.g., a series with drift) may affect the distribution of the error terms and thereby affect statistical inference in the associated model. Third, the postulated exogeneity of the policy instruments is potentially misleading and deserves careful consideration. If the policy instruments are not exogenous, inferences with an MCI that assumes exogeneity may be biased. Fourth, parameter constancy turns on all three of the aforementioned issues. Empirically nonconstant weights may arise from mis-specified dynamics, improper treatment of nonstationarity, or incorrect exogeneity assumptions. Because the MCI is designed for policy, structural invariance of the weights is important and requires valid super exogeneity. Finally, significant omitted variables in the estimated relationship between $v$ and $e$ and $R$ may affect dynamics, cointegration, exogeneity, and parameter constancy in that estimated relationship. Readers not concerned with the technical details of these arguments may skip directly to Section 3.6.

To examine these five issues more concretely, this section employs a simple analytical framework for assessing the relationship between an MCI and the empirical

model on which it is based. Specifically, the weights $\theta_{v, e}$ and $\theta_{v, R}$ in (1) are unknown a priori and must be estimated. These weights are typically derived from coefficient estimates in an empirical model relating $v$ to $e, R$, and other variables. The following pair of equations serves to illustrate:

$$
\begin{aligned}
& y_{t}=\mu_{1}+\left(\pi_{11}+1\right) y_{t-1}+\pi_{12} p_{t-1}+\pi_{13} R_{t-1}+\pi_{14} e_{t-1}+\pi_{15} q_{t-1}+\varepsilon_{1 t} \\
& p_{t}=\mu_{2}+\pi_{21} y_{t-1}+\left(\pi_{22}+1\right) p_{t-1}+\pi_{23} R_{t-1}+\pi_{24} e_{t-1}+\pi_{25} q_{t-1}+\varepsilon_{2 t} .
\end{aligned}
$$

The variables $y$ and $p$ are the logarithms of real domestic output (GDP) and the 
domestic price level $(P)$, which are potential choices for the target variable $v ; q$ is the single exogenous variable additional to $e$ and $R$; and $\varepsilon_{1 t}$ and $\varepsilon_{2 t}$ are the two errors, which for expositional convenience are assumed serially uncorrelated. The coefficient on the $j$ th variable in the $i$ th equation is $\pi_{i j}$, except that the coefficients on the two lagged dependent variables include unities for notational convenience below; and $\mu_{1}$ and $\mu_{2}$ are the constant terms in the two equations. The system is dynamic, with lags of $y$ and $p$ appearing in both equations. The policy instruments $e$ and $R$ enter at the first lag only, as do $q$ and the lags of $y$ and $p$. In practice, current-dated values of $e, R$, and $q$ may enter (3)-(4) as well, as may additional lags of all variables. Their presence complicates the algebraic analysis and bears on the issue of exogeneity (see Section 3.3), but otherwise poses no conceptual difficulties. Despite its simplicity, the system (3)-(4) embeds most important aspects of estimated MCI models, as shown below.

\subsection{Dynamics}

Because equations (3) and (4) are dynamic relationships, the effects of monetary policy depends on the time horizon. Impact, interim, and long-run multipliers can be constructed to characterize those effects. Choosing the weights (or multipliers) in an MCI requires specifying the time horizon of interest.

For the exchange rate, a whole sequence of GDP-related multipliers $\left\{\theta_{y, e, k} ; k=\right.$ $0,1,2, \ldots\}$ is defined by (3)-(4). The impact multiplier $\theta_{y, e, 0}$ is zero; the first-lag multiplier $\theta_{y, e, 1}$ is $\pi_{14} ; \theta_{y, e, k}$ is the $k$-period ahead interim multiplier; and the long-run multiplier $\theta_{y, e, \infty}$ is:

$$
\theta_{y, e, \infty}=\frac{-\pi_{14} \pi_{22}+\pi_{12} \pi_{24}}{\pi_{11} \pi_{22}-\pi_{12} \pi_{21}}
$$

For the interest rate, the impact and first-lag multipliers are zero and $\pi_{13}$ respectively, and the long-run multiplier is:

$$
\theta_{y, R, \infty}=\frac{-\pi_{13} \pi_{22}+\pi_{12} \pi_{23}}{\pi_{11} \pi_{22}-\pi_{12} \pi_{21}}
$$

Similar multipliers exist for $p$ as the target variable.

In any MCI, some pair of multipliers must be chosen as the weights $\theta_{v, e}$ and $\theta_{v, R}$, where that choice reflects the horizon of interest. Current practice varies across central banks. For example, the Swedish Central Bank constructs the MCI weights as the 4-quarter interim income multipliers from a quarterly econometric model, i.e., $\theta_{y, e, 4}$ and $\theta_{y, R, 4}$ in our notation. The Central Bank of Norway and the Bank of Canada base their MCI weights on horizons of approximately 8 quarters and 6- 8 quarters 
respectively. See Hansson and Lindberg (1994, p. 16) and the monthly inflation report of the Swedish Central Bank, Jore (1994) and the quarterly inflation report of the Central Bank of Norway, and Freedman (1994, p. 469).

Interim multipliers for transformations of $y_{t}$ and $p_{t}$ can be derived as well. In particular, the MCI with respect to inflation $\Delta p$ could be constructed from the two sequences:

$$
\theta_{\Delta p, e, k}=\theta_{p, e, k}-\theta_{p, e, k-1}(k=0,1,2, \ldots), \text { with } \theta_{p, e,-1}=0
$$

and:

$$
\theta_{\Delta p, R, k}=\theta_{p, R, k}-\theta_{p, R, k-1}(k=0,1,2, \ldots), \text { with } \theta_{p, R,-1}=0 .
$$

If the levels of output and prices are not of interest per se, the relevant interim multipliers for $\Delta y_{t}$ and $\Delta p_{t}$ can be obtained more directly. Subtracting $y_{t-1}$ from both sides of (3) and $p_{t-1}$ from both sides of (4), the system (3)-(4) then has $\Delta y_{t}$ and $\Delta p_{t}$ as dependent variables:

$$
\begin{aligned}
\Delta y_{t} & =\mu_{1}+\pi_{11} y_{t-1}+\pi_{12} p_{t-1}+\pi_{13} R_{t-1}+\pi_{14} e_{t-1}+\pi_{15} q_{t-1}+\varepsilon_{1 t} \\
\Delta p_{t} & =\mu_{2}+\pi_{21} y_{t-1}+\pi_{22} p_{t-1}+\pi_{23} R_{t-1}+\pi_{24} e_{t-1}+\pi_{25} q_{t-1}+\varepsilon_{2 t}
\end{aligned}
$$

In (9) and (10), the new target variables appear explicitly as the left-hand side variables. Even so, (9)-(10) is an isomorphic transformation of (3)-(4), with the residuals being unaffected. Conversely, the popular strategy of differencing a model involves restrictions on the system and may induce loss of information. For example, $\pi_{22}=0$ is required to obtain an inflation equation from (10), i.e., with no price level appearing. The restrictions imposed by differencing can be tested, although the correct critical values depend upon the stationarity or nonstationarity of the data, as discussed below.

Even if the primary focus in an MCI is the medium run, internal consistency requires that the whole sequence of interim multipliers be bounded. Otherwise, a trivial adjustment of a policy instrument eventually could obtain any level of GDP. Hence, it seems a sensible requirement that operational MCIs be based on a system that is stable in the usual sense, having finite long-run multipliers. For (3)-(4), the system should have its roots within the unit circle, implying that the denominator in (5) and (6) is nonzero. 


\subsection{Data Nonstationarity}

The mathematical property of the system being stable relates directly to the statistical concept of data stationarity. The empirical nonstationarity of many economic time series raises several issues, including the possibility of stationary relations between nonstationary economic series (cointegration). As with stationary data, important distinctions exist between short-, medium-, and long-run multipliers. Further, common empirical procedures such as differencing can confound short- and long-run effects. This subsection examines three possible characterizations of the system (3)(4) with nonstationary data and considers the implications for estimated multipliers. The characterizations of the system also provide a natural bridge to the subsequent subsection on exogeneity. Engle and Granger (1987) and Johansen (1991) provide the underlying concepts and analytical structure for this subsection.

A few statistical concepts are helpful for discussing stationarity and nonstationarity. A variable is said to be (weakly) stationary if its mean, variance, and autocovariances are constant over time. If output, prices, the interest rate, the exchange rate, and $q$ are all stationary, then the system (3)-(4) is stable. The stable framework is limiting empirically because many macro-economic time series appear to be nonstationary, being well approximated by models with stochastic trends. Nonstationary variables that can be made stationary through differencing are called integrated variables. If a variable $s_{t}$ is made stationary by differencing just $d$ times, $s_{t}$ is said to be integrated of order $d$, denoted $s_{t} \sim I(d)$; and therefore $\Delta^{d} s_{t}$ is $I(0)$ (stationary). Many macro-economic series appear to be $I(1)$ or (at most) $I(2)$.

Stationarity and nonstationarity are important concepts for an MCI because the time series properties of the variables in the model (3)-(4) affect the distribution of the error terms. Specifically, the error terms are not stationary unless (3) and (4) are balanced equations, that is, unless the left-hand side variables have the same temporal properties as the right-hand side variables. Without balance, the latter variables cannot in principle explain the dominant features of the former. For example, if $y_{t}$ in $(3)$ is $I(1)$, then some variable on the right-hand side of (3) also must be $I(1)$ to ensure that that equation's error is stationary. Balance is a necessary (but not sufficient) condition for the error term to be stationary, and stationary errors are required for conventional estimation techniques. Economically, nonstationary errors are difficult to interpret, especially to the extent that these errors are being made by optimizing economic agents.

To illustrate the implications of nonstationarity in greater detail, suppose that both endogenous variables in (3)-(4) are $I(1)$. That is, output $y$ and prices $p$ each have a stochastic trend, which can be removed by differencing the series once. To facilitate analysis, equations (3)-(4) can be rewritten as (9)-(10) in matrix notation: 


$$
\Delta w_{t}=\mu_{w}+\pi_{w w} w_{t-1}+\pi_{w z} z_{t-1}+\varepsilon_{w, t},
$$

where $w_{t}=\left(y_{t}, p_{t}\right)^{\prime}, \mu_{w}=\left(\mu_{1}, \mu_{2}\right)^{\prime}, z_{t}=\left(R_{t}, e_{t}, q_{t}\right)^{\prime}, \varepsilon_{w, t}=\left(\varepsilon_{1 t}, \varepsilon_{2 t}\right)^{\prime}$, the coefficient matrix $\pi_{w w}$ on the lagged endogenous variables is:

$$
\pi_{w w}=\left[\begin{array}{ll}
\pi_{11} & \pi_{12} \\
\pi_{21} & \pi_{22}
\end{array}\right],
$$

and that on the three exogenous variables is:

$$
\pi_{w z}=\left[\begin{array}{lll}
\pi_{13} & \pi_{14} & \pi_{15} \\
\pi_{23} & \pi_{24} & \pi_{25}
\end{array}\right] .
$$

The representation (11) may be simplified further as:

$$
\Delta w_{t}=\mu_{w}+\pi_{w} x_{t-1}+\varepsilon_{w, t},
$$

where $x_{t}$ is the full set of variables $\left(w_{t}^{\prime}: z_{t}^{\prime}\right)^{\prime}\left[=\left(y_{t}, p_{t}: R_{t}, e_{t}, q_{t}\right)^{\prime}\right]$, and $\pi_{w}$ is the coefficient matrix $\left(\pi_{w w}: \pi_{w z}\right)$. This formulation proves useful in discussing both cointegration and exogeneity.

Without further restrictions on the system, (14) is unbalanced because $\Delta w_{t}$ is $I(0)$ whereas $x_{t-1}$ is $I(1)$. To make progress in estimating and interpreting (14), that subsystem is rewritten in terms of $I(0)$ variables so as to make it balanced. Doing so implies testable restrictions involving cointegration. Three cases meet the requirement of a balanced system.

Case 1 Two cointegrating relationships.

Case 2 One cointegrating relationship.

Case 3 No cointegration.

Throughout, $z_{t}$ is assumed to be $I(1)$ or $I(0)$, and $w_{t}$ is assumed to be $I(1)$. In practice, one or both variables in $w_{t}$ might be $I(0)$, thereby resulting in (trivial) cointegrating vectors.

Cointegration implies that $\pi_{w}$ may be written as $\alpha_{w} \beta^{\prime}$, the product of two full-rank matrices, so (14) may be rewritten as:

$$
\Delta w_{t}=\mu_{w}+\alpha_{w} \beta^{\prime} x_{t-1}+\varepsilon_{w, t},
$$

where $\alpha_{w}$ is a $2 \times r$ matrix of error correction feedback coefficients; $\beta$ is a $5 \times r$ matrix of cointegrating vectors; and $r$ is the number of cointegrating relationships, 
which is also the rank of $\pi_{w}$. Here, $r$ is 0,1 , or 2 . Cointegration means that $\beta^{\prime} x_{t-1}$ is stationary, thereby making (15) balanced. Suitably partitioning, $\pi_{w}$ may be rewritten as:

$$
\pi_{w}=\left(\pi_{w w}, \pi_{w z}\right)=\left(\alpha_{w} \beta_{w}^{\prime}, \alpha_{w} \beta_{z}^{\prime}\right)
$$

where $\beta_{w}$ is a $2 \times r$ matrix of long-run coefficients for the endogenous variables, and $\beta_{z}$ is a $3 \times r$ matrix of the long-run multipliers for the exogenous variables.

In Case 1, there are two cointegrating vectors, corresponding to two separate long-run relationships. If either output or prices appears in the cointegrating vectors $\left(\beta_{w} \neq 0\right)$, one or more of the exogenous variables $z_{t}$ must be $I(1)$, and $\beta_{z}$ must be nonzero. This situation is consistent with several empirically important situations. For example, both the exchange rate and the interest rate might be $I(1)$ but cointegrated with output and/or prices. This is similar to the stationary example in the sense that a full set of interim multipliers may exist for output, the deflator, and for linear transformations thereof. Or, the additional exogenous variable $q_{t}$ might be $I(1)$ and cointegrated with output and prices.

Case 1 includes another possibility: $z$ might enter the cointegrating relationships while $w$ does not $\left(\beta_{w}=0\right)$. The exchange rate, the interest rate, and $q_{t}$ might be $I(0)$ outright; or some or all of these variables might be $I(1)$ with two stationary linear combinations. In either situation, the system can be written in terms of output growth $\Delta y_{t}$ and inflation $\Delta p_{t}$ :

$$
\begin{aligned}
& \Delta y_{t}=\mu_{1}+\pi_{13} R_{t-1}+\pi_{14} e_{t-1}+\pi_{15} q_{t-1}+\varepsilon_{1 t} \\
& \Delta p_{t}=\mu_{2}+\pi_{23} R_{t-1}+\pi_{24} e_{t-1}+\pi_{25} q_{t-1}+\varepsilon_{2 t} .
\end{aligned}
$$

From (17)-(18), an MCI could be constructed for output growth or inflation, although doing so would depend upon knowing the structure of cointegration involving $R, e$, and $q$. In particular, if the exchange rate $e$ and the interest rate $R$ are real, both variables might be stationary, inducing two trivial cointegrating relationships for $z$.

In Case 2, there is only one cointegrating vector. In principle, the cointegrating relationship may involve $w$ alone; economically, it is likely to include $z$ because prices and real output are unlikely to form a long-run relationship by themselves. As in Case 1 , cointegration could involve $z$ alone. The interpretation of the cointegrating vector $\beta$ depends on the structure of $\alpha_{w}$ [defined as $\left(\alpha_{11}, \alpha_{21}\right)^{\prime}$ ] and $\beta$ [defined as $\left.\left(\beta_{11}, \beta_{12}, \beta_{13}, \beta_{14}, \beta_{15}\right)^{\prime}\right]$. If $\beta_{11} \neq 0$ and $\alpha_{21}=0$ (implying $\alpha_{11} \neq 0$ ), $\beta^{\prime} x$ represents a long-run output relationship, with output alone adjusting to disequilibria in the system. Prices are weakly exogenous for $\beta$, as discussed below. Conversely, if $\beta_{12} \neq 0$ and $\alpha_{11}=0$ (implying $\alpha_{21} \neq 0$ ), $\beta^{\prime} x$ is interpretable as a price relationship, with 
prices alone adjusting to disequilibria. As a third possibility, both $\alpha_{11}$ and $\alpha_{21}$ might be nonzero, with output and prices both adjusting to disequilibria. While $\beta^{\prime} x$ itself represents an equilibrium solution, it does not indicate which variable adjusts to which, or whether both adjust.

In Case 3, there is no cointegration: $\pi_{w}=0$, implying that $w$ is a random walk. With more general dynamics, lags of $\Delta w$ and $\Delta z$ may enter (14), even though lack of cointegration excludes the presence of the levels $w$ and $z$.

As a partial system, (14) precludes discovering more cointegrating vectors than the number of equations in (14) itself, even if such cointegrating vectors exist. That argues for analysis of the full set of variables $\left(w^{\prime}, z^{\prime}\right)^{\prime}$ in a closed system, which inter alia allows testing the assumed weak exogeneity of $z$ and leads to the next subsection.

\section{$3.3 \quad$ Exogeneity}

Equation (14) for $w$ is a natural framework for analyzing and estimating weights for an MCI. However, (14) is an open subsystem and provides only partial information on the (closed) full system for $\left(w^{\prime}, z^{\prime}\right)^{\prime}$. The structure of the subsystem for $z$ also may directly affect the constructed MCI, even though that subsystem is not specified. Specifically, disequilibria involving $w$ (as measured by cointegrating relationships) may influence $z$, in which case the estimated MCI weights are no longer interpretable as partial derivatives. Weak exogeneity of $z$ for the cointegrating vectors $\beta$ is related to whether or not this feedback occurs. For simplicity, the weights $\theta_{v, e}$ and $\theta_{v, R}$ are assumed below to correspond to the long-run multipliers, depending on $\beta$ alone. In practice, the weights are typically interim multipliers and so involve parameters for short-term dynamics as well. Weak exogeneity is testable, requiring information about the full system. This subsection completes the system and analyzes how the presence or lack of exogeneity affects the interpretation of an MCI.

To create the full system, equations for the exogenous variables $z$ are required. Without loss of generality in a linear single-lag framework, the subsystem for $z$ parallels (14) as:

$$
\Delta z_{t}=\mu_{z}+\pi_{z} x_{t-1}+\varepsilon_{z, t}
$$

where $\mu_{z}$ is the constant term, $\pi_{z}$ is the matrix of coefficients on $x_{t-1}$, and $\varepsilon_{z, t}$ is the error. Combining (14) and (19) obtains a closed system for $x$ :

$$
\Delta x_{t}=\mu+\pi x_{t-1}+\varepsilon_{t}
$$

where $x_{t}$ is the full set of variables $\left(w_{t}^{\prime}, z_{t}^{\prime}\right)^{\prime}, \mu$ is the vector of intercepts $\left(\mu_{w}^{\prime}, \mu_{z}^{\prime}\right)^{\prime}$ in the system for $x_{t}, \pi$ is $\left(\pi_{w}^{\prime}, \pi_{z}^{\prime}\right)^{\prime}$, and $\varepsilon_{t}$ is the corresponding vector of disturbances 
$\left(\varepsilon_{w, t}^{\prime}, \varepsilon_{z, t}^{\prime}\right)^{\prime}$. For simplicity, the errors $\varepsilon_{t}$ are assumed to be normally distributed with zero mean and a constant variance $\Omega$, partitioned as:

$$
\Omega=\left[\begin{array}{ll}
\Omega_{w w} & \Omega_{w z} \\
\Omega_{z w} & \Omega_{z z}
\end{array}\right] .
$$

Paralleling the subsystem (15), (20) may be written in terms of a feedback matrix $\alpha$ and a matrix of cointegrating vectors $\beta$ :

$$
\Delta x_{t}=\mu+\alpha \beta^{\prime} x_{t-1}+\varepsilon_{t} .
$$

While formally similar, the subsystem (15) and closed system (22) differ in two important respects. First, (22) may have as many as five cointegrating vectors: the maximum in (15) is two. The matrices $\alpha$ and $\beta$ in (22) are of dimension $5 \times r$, where $r$ is the number of cointegrating vectors in (22), which may differ from the number of cointegrating vectors in (15). Second, the matrix $\alpha$ in (22) includes not only $\alpha_{w}$ [the feedback matrix in (15)] but also $\alpha_{z}$, the matrix of feedback coefficients for the equations determining the exogenous variables $z$.

The matrix $\alpha_{z}$ plays a critical role in the exogeneity of $z$, as follows (without loss of generality) from rewriting the system (22) as a conditional model for $\Delta w_{t}$ and a marginal model for $\Delta z_{t}$ :

$$
\begin{aligned}
\Delta w_{t} & =\delta+\gamma_{1} \Delta z_{t}+\gamma_{2} \beta^{\prime} x_{t-1}+\zeta_{w, t} \\
\Delta z_{t} & =\mu_{z}+\alpha_{z} \beta^{\prime} x_{t-1}+\varepsilon_{z, t} .
\end{aligned}
$$

The matrix $\alpha$ is partitioned as $\left(\alpha_{w}^{\prime}, \alpha_{z}^{\prime}\right)^{\prime}$, and the coefficients $\left(\delta, \gamma_{1}, \gamma_{2}\right)$ are functions of the coefficients in (22) and the submatrices of $\Omega .^{1}$ If $\alpha_{z}=0$ and $\gamma_{1}=0$, then (23) contains all the information on $\beta$, and (23) simplifies to (15). The restriction $\alpha_{z}=0$ implies that $R_{t}, e_{t}$, and $q_{t}$ are weakly exogenous for the matrix of cointegrating vectors $\beta$ : namely, (24) contains no information on $\beta$. The restriction $\gamma_{1}=0$ reflects the particular dynamic specification in (15) and is not directly germane to exogeneity.

Weak exogeneity of $z$ for $\beta$ is testable, e.g., by estimating (22) and testing that $\alpha_{z}=0$. If exogeneity is not rejected, analysis can proceed within the confines of the conditional model (23) alone. If weak exogeneity is rejected, $z_{t}$ should be modeled jointly with output and prices. Otherwise, inference about the cointegrating vector (and so about the MCI weights) is likely to be inefficient and possibly invalid.

Rejection of the weak exogeneity of $z_{t}$ for $\beta$ has even more immediate consequences, in that the MCI is no longer a well-defined concept: there are no multipliers

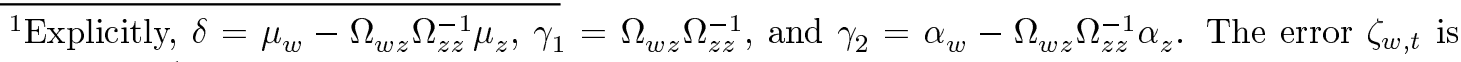
$\varepsilon_{w, t}-\Omega_{w z} \Omega_{z z}^{-1} \varepsilon_{z, t}$.
} 
to calculate because the policy instruments cannot be treated as given. Empirically, policy instruments seem likely to respond to past disequilibria in output and price relationships, in which case weak exogeneity does not hold. Additionally, if weak exogeneity does not hold, the closed system (22) may involve more than two cointegrating relationships, and inflation and output may enter those relationships. If so, the cointegrating vectors in the subsystem (15) are typically linear combinations of the full set of cointegrating vectors, thereby confounding the economic interpretation of the former. ${ }^{2}$

In the examples used so far, weak exogeneity implies strong exogeneity: namely, $\alpha_{z}=0$ rules out all feedback from $w$ to $z$, and not just feedback from the level of $w$. Empirical models often involve higher-order dynamics. If they do, then weak exogeneity and strong exogeneity are distinct concepts; see Engle, Hendry, and Richard (1983) for details. Models with higher-order dynamics may include lags of $\Delta w$ and $\Delta z$ in both the conditional model and the marginal model. If lags of $\Delta w$ are significant in the marginal model for $z$, then $w$ Granger-causes $z$ through those lags. Strong exogeneity does not hold, as it requires Granger non-causality. Weak exogeneity of $z$ for $\beta$ holds if $\alpha_{z}=0$, even if Granger causality is present. If weak exogeneity for $\beta$ holds but strong exogeneity does not, impact and long-run MCI weights can be validly constructed from the conditional model, but in general the interim multipliers can not. Interim multipliers constructed from the conditional model alone are biased because they fail to account for feedback effects from (e.g.) inflation to the interest rate and the exchange rate. If the exchange rate $e$ is real, it may be inherently endogenous in the inflation equation because $e$ contains the domestic price level.

\subsection{Parameter Constancy}

Parameter constancy turns on all three of the aforementioned issues. Empirically nonconstant weights may arise from mis-specified dynamics, improper treatment of nonstationarity, or incorrect exogeneity assumptions. Because the MCI is designed for policy, structural invariance of the weights is important and requires valid super exogeneity. A priori, the output and price equations (3) and (4) are likely to be nonconstant because they constitute a reduced form. Empirically, parameter constancy can be evaluated by Chow (1960) and related statistics and by recursive estimation of the coefficients, as in Section 4 below.

\footnotetext{
${ }^{2}$ With little loss of clarity, the discussion above ignores the implied algebraic complications for $\alpha, \beta$, and $r$ in (15) and (22).
} 


\subsection{Omitted Variables}

Significant omitted variables in the estimated relationships between the target $v$ and $e$ and $R$ may affect dynamics, exogeneity, cointegration, and parameter constancy in those estimated relationships. While the range of potential mis-specifications is vast, a few examples clarify the empirical importance of omitted variables in (3)-(4).

Mis-specification by omitted variables can bias coefficient estimates of included dynamic variables. Relatedly, Granger (1969) notes that Granger causality is not invariant to the number of variables in the system.

The presence or lack of cointegration may be affected by what is included or excluded in the set of exogenous variables $q$. In Section 3.2, the choice of variables in $q$ is treated as given, yet it need not be. For instance, for a set of U.K. money demand data, Hendry and Mizon (1993) and Hendry and Doornik (1994) find two cointegrating vectors, one being a standard money demand relationship and the other being a relationship between $y, \Delta p$, and a trend. Analyzing the same data but without a trend, Ericsson, Campos, and Tran (1990) find only the first cointegrating vector. Significantly, a trend is excluded from (3)-(4).

Equally, domestic prices may cointegrate with other variables, such as unit labor costs, foreign prices, and energy prices; see Juselius (1992) for Denmark, de Brouwer and Ericsson (1995) for Australia, and Franz and Gordon (1993) and Ericsson (1994b) for the United States. If such variables are excluded, then levels effects are ignored. Coefficient estimates on growth rates are interpreted as capturing long-run effects, whereas they are short-run in fact.

Significant omitted variables imply biases on estimated coefficients. Those biases are likely to change over time as data correlations change, thereby inducing parameter nonconstancy.

\subsection{Interpreting MCIs When the Assumptions Are Valid}

Interpretation of an MCI as an indicator of monetary policy stance is fraught with difficulty, even when the assumptions involving dynamics, cointegration, exogeneity, parameter constancy, and omitted variables are satisfied. Current use and interpretation of an MCI in policy assumes a direct and unequivocal relationship between the actual instruments and the variables $e$ and $R$. Economically, variables other than the policy instruments also may play important roles in determining $e$ and $R$. For example, changes in world oil and commodity prices may alter a country's terms of trade, thereby affecting $e$. The MCI would then change, even if monetary policy stance remained unchanged. Likewise, changes in world interest rates and inflation rates and in domestic asset portfolio preferences may alter $R$, and so the MCI. The variables 
from which the MCI is constructed may reflect phenomena other than just direct monetary policy, so movements in the MCI are not tied unequivocally to changes in monetary policy stance. So, by using an MCI as an indicator of monetary policy stance, a central bank could be misled into adopting an overly tight (or loose) monetary policy, simply because some external shock not related to domestic monetary policy affected $e$ or $R$, thereby contaminating the measured MCI.

At more conceptual level, $e$ and $R$ have been treated as policy instruments throughout this paper. In practice, $e$ and $R$ are operational targets, with variables such as the discount rate being the actual policy instruments. This distinction between operational targets and policy instruments introduces an additional link in the monetary transmission mechanism, through which non-policy variables might affect $e$ and $R$.

Finally, an MCI by itself is not sufficient to judge whether monetary conditions are too loose or too tight for a given policy objective. For example, the exogenous variables $q$ influence the ultimate target variables but not the calculated MCI. Hence, policy makers cannot look at the MCI exclusively, but have to make explicit or implicit assumptions about the monetary transmission mechanism before surmising the tightness of monetary conditions. A complete empirical model of the monetary transmission mechanism is typically needed - equations (3)-(4) in our framework. Specifically, when using an MCI as an operational target, such a model pins down a path for the MCI that is consistent with the policy target (e.g., inflation) and the projected development of the exogenous variables $q$. Subsequent shocks may affect the policy target directly but leave the actual MCI unchanged, in which case the target path for the MCI will need to be recalculated.

\section{A Brief Appraisal of Models for Three MCIs}

The most accessible econometric studies leading to MCIs are Duguay (1994) for Canada, Hansson (1993) for Sweden, and Jore (1994) for Norway. The analytical model (3)-(4) above captures the essential structure of these empirical models. Thus, this section examines these models qua models for building MCIs, analyzing them in terms of the issues in Section 3: dynamics, integration and cointegration, exogeneity, parameter constancy, and omitted variables. In practice, cointegration and constancy are particularly important issues. Many series for the three empirical models are in differences alone, or are detrended, so possible cointegration is ignored. One central

coefficient is statistically nonconstant in the model for the Swedish MCI, and the MCI weights for Norway are numerically very sensitive to the choice of sample period. 


\subsection{Canada}

The Canadian MCI is constructed from estimates of output equations similar to (3), with the quarterly aggregate demand models in Duguay (1994) being representative; see Freedman (1994). The estimated model has extensive albeit restrictive dynamics, possible cointegration is ignored, and exogeneity and parameter constancy remain untested.

Dynamics appear in two forms: the real interest rate enters as a two-year change $\left(\Delta_{8} R_{t}\right)$, and the real exchange rate as its three-year change $\left(\Delta_{12} e_{t}\right)$; see Duguay (1994, Table 1). ${ }^{3}$ The model also includes a measure of fiscal stance (the change in a government surplus relative to potential GDP), the current and lagged growth rates of U.S. GDP, and an average growth rate of real commodity prices, all of which belong in $q$. Granger causality is not tested, even though lagged inflation and output growth might well affect any of these variables empirically.

In Duguay (1994), the output equation is in growth rates and differences alone. The data series (including the interest rate) are assumed to be $I(1)$, and cointegrating relationships are precluded. Issues of integration and cointegration are not addressed, and in particular the assumed null hypothesis of no cointegration is not tested. Relatedly, additional (omitted) variables might be required to establish cointegration. For instance, domestic prices might be cointegrated with unit labor costs and/or with foreign prices (see Section 3.5 above), yet levels of these variables are excluded from the model.

The estimated demand equation contains contemporaneous effects of the real interest rate and the real exchange rate. Because the model is estimated by OLS, the model is interpreted as a conditional equation similar to the output equation in (23) above. The assumption of weak exogeneity remains implicit and is not tested.

Parameter constancy is not tested, although estimates for a full sample (1975Q11990Q4) and a subsample (1980Q1-1990Q4) are reported. Equation standard errors are very similar for the two subsamples, supporting constancy. Other splits of the sample may be relevant, so a more detailed recursive analysis would be desirable.

\subsection{Sweden}

The Swedish Central Bank publishes an MCI in its inflation report; see Hansson and Lindberg (1994). This subsection re-estimates the model in Hansson (1993) for the Swedish MCI and finds that a central parameter is empirically nonconstant. That

\footnotetext{
${ }^{3}$ Formally embedding Duguay's model within our framework would require additional lags of all variables in (3) and (4). With the exception of strong exogeneity (as described above), the conceptual issues remain the same.
} 
observed difficulty hinders reliable calculation of weights for an MCI. Thus, while the other issues discussed in Section 3 still bear on the calculated MCI, this subsection (and likewise, Section 4.3 below) focuses on the issue of empirical constancy.

The quarterly model underlying the Swedish MCI takes the form:

$$
\begin{aligned}
y_{t}= & a_{1} y_{t-1}+a_{2} y_{t-2}+a_{3} \Delta p_{t}+a_{4} R_{t-1}+a_{5} e_{t-1}+\varepsilon_{1 t} \\
\Delta p_{t}= & b_{1} \Delta p_{t-1}+\cdots+b_{4} \Delta p_{t-4}+b_{5} y_{t} \\
& \quad+b_{6} \Delta p_{t}^{*}+\cdots+b_{16} \Delta p_{t-10}^{*}+\varepsilon_{2 t}
\end{aligned}
$$

where $y$ is a logarithmic measure of the deviation in output from a linear trend, $\Delta p$ is CPI inflation, $R$ is a real short-term interest rate, $e$ is the logarithm of the real exchange rate, $\Delta p^{*}$ is the growth rate of foreign prices measured in domestic currency, and $\left\{a_{i}\right\}$ and $\left\{b_{i}\right\}$ are coefficients. The trend in output is estimated from an auxiliary regression:

$$
G D P_{t}=\tau_{0}+\tau_{1} t+\eta_{t}
$$

where $\eta_{t}$ is an error, and $\tau_{0}$ and $\tau_{1}$ are coefficients. The variable $y_{t}$ is calculated as $\ln \left(G D P_{t} / G \widehat{D P} P_{t}\right)$, where $\widehat{G D P_{t}}$ is the fitted value from OLS estimation of (27). Thus, this model implicitly assumes that GDP is stationary around a deterministic trend. If GDP is not, the coefficient estimates may be ill-behaved.

The simultaneous equations model (25)-(26) fits into our framework, since it can be rewritten as (3)-(4), with $q$ containing both the trend from the auxiliary regression (27) and current and lagged values of $\Delta p^{*}$ from (26). Using data made available to us by the Swedish Central Bank, we reproduced the results in Hansson (1993); our Appendix A provides details. Looking at parameter constancy first, Figure 1 plots the recursively estimated coefficient of the trend term $\left(\tau_{1}\right)$ in equation $(27)$, together with plus-or-minus twice the coefficient's estimated standard errors. At face value, (27) is both numerically and statistically highly nonconstant over the sample. The recursively estimated coefficient halves from 1975 to 1984 and then returns to its initial value by the end of the sample. These fluctuations are well outside the estimated $95 \%$ confidence intervals plotted in the figure.

Figure 1 also plots the one-step residuals and the corresponding equation standard errors: $\left\{\hat{\eta}_{t}\right\}$ from (27), and $\left\{0 \pm 2 \hat{\sigma}_{t}\right\}$ in a common notation. Here, the subscript $t$ refers both to the final observation of the estimation subsample and to the period for which the variable $\hat{\eta}_{t}$ is calculated. The recursive equation standard errors more than double over the sample - break-point Chow statistics reject at the $0.01 \%$ level for most sample splits. Because of this nonconstancy, inferences with an MCI are likely 

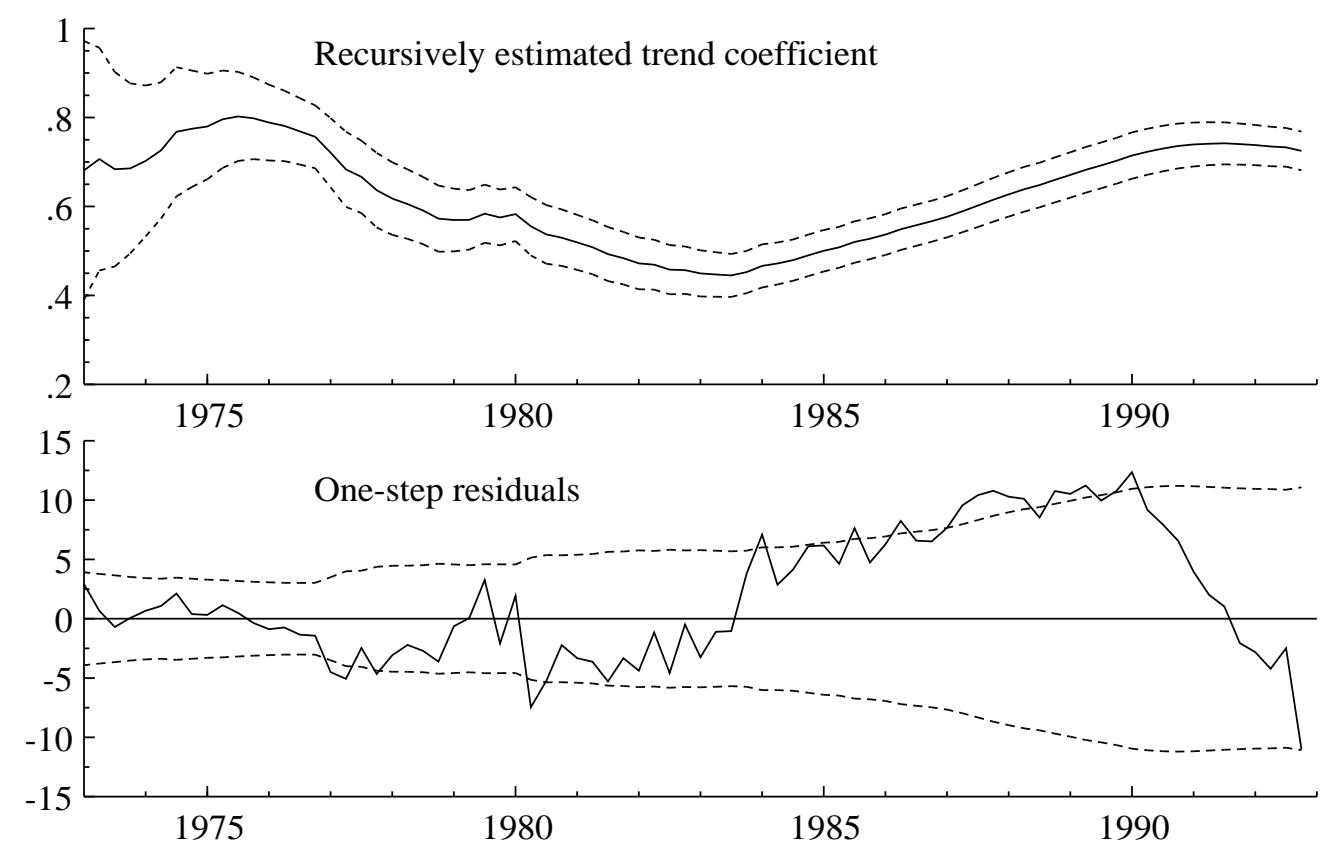

Figure 1: The recursively estimated coefficient on the trend (-) in the Swedish MCI model with \pm 2 times the estimated standard errors $(--)$, and one-step residuals $(-)$ with \pm 2 times the corresponding equation standard errors $(--)$.

to be affected by which sample happened to be used for calculating the weights. Equally, because of the nonconstancy, the calculated MCI is unlikely to be useful in policy, as a leading indicator, or for forecasting.

The nonconstancy also invalidates the assumption of trend stationarity, which underlies the ensuing estimation of the dynamic system (25)-(26). Nonconstancy thus affects the economic interpretation of the Swedish model. Because the linear trend model fits poorly, it is unclear what detrended output $y_{t}$ measures and hence what variable the constructed MCI is meant to target.

That said, the residuals $\left\{\hat{\eta}_{t}\right\}$ in (27) are highly autocorrelated and heteroscedastic, so inferences about the estimated trend coefficient using OLS estimated standard errors are likely to be biased themselves. As an alternative, the trend might be incorporated explicitly in $q$, as in Hendry and Mizon (1993) and Hendry and Doornik (1994), where it enters a cointegrating relation between $y$ and $\Delta p$. 
Table 1: OLS estimates for the output equation of the Norwegian MCI model over the original sample and an extended sample.

\begin{tabular}{|c|c|c|c|c|}
\hline \multirow[t]{3}{*}{ Variable } & \multicolumn{4}{|c|}{ Estimation Period } \\
\hline & \multicolumn{2}{|c|}{ 1985Q1-1993Q4 } & \multicolumn{2}{|c|}{ 1985Q1-1994Q4 } \\
\hline & Coefficient & $t$ ratio & Coefficient & $t$ ratio \\
\hline$y_{t-1}$ & -0.124 & -1.4 & -0.151 & -1.6 \\
\hline$R_{t-2}$ & -0.349 & -2.0 & -0.221 & -1.5 \\
\hline$\Delta \Delta e_{t}$ & 0.302 & 2.7 & 0.241 & 2.1 \\
\hline$e_{t-1}$ & 0.163 & 1.8 & 0.017 & 0.2 \\
\hline \multirow[t]{2}{*}{ Constant } & 0.028 & 2.2 & 0.016 & 1.6 \\
\hline & $R^{2}=0.32$ & $\hat{\sigma}=1.16 \%$ & $R^{2}=0.25$ & $\hat{\sigma}=1.21 \%$ \\
\hline
\end{tabular}

\subsection{Norway}

The MCI published in the Central Bank of Norway's inflation report is based on a single-equation model of aggregate demand from Jore (1994). This subsection shows that the numerical weights for the MCI are highly sensitive to the estimation sample period, and different estimated weights result in different inferences about monetary conditions.

The quarterly model underlying the Norwegian MCI takes the form:

$$
y_{t}=c_{0}+c_{1} y_{t-1}+c_{2} R_{t-2}+c_{3}\left(e_{t}+e_{t-2}\right)+c_{4} e_{t-1}+\varepsilon_{1 t},
$$

for coefficients $\left\{c_{i}\right\}$. As with the Swedish model, $y_{t}$ is detrended output; but the Hodrick-Prescott filter is used instead of a linear trend. Even so, the HP filter does closely approximate a linear trend, as the chosen smoothing parameter $\lambda$ is large: $\lambda=100000$, compared with the value of $\lambda=1600$ frequently used in the literature. The estimated equation in Jore (1994) is reproduced on the left-hand side of Table 1, albeit with $\Delta y_{t}$ as the dependent variable and with a reparameterization of $e$ to separate short-run and long-run effects. The only explanatory variables included are the two policy variables $R$ and $e$ themselves; and the sample period is short (36 observations).

Jore (1994) mentions that numerical instability of estimated coefficients arises when the sample is extended to include earlier observations. Indeed, a reducedform aggregate demand equation is likely to be nonconstant because of deregulation 


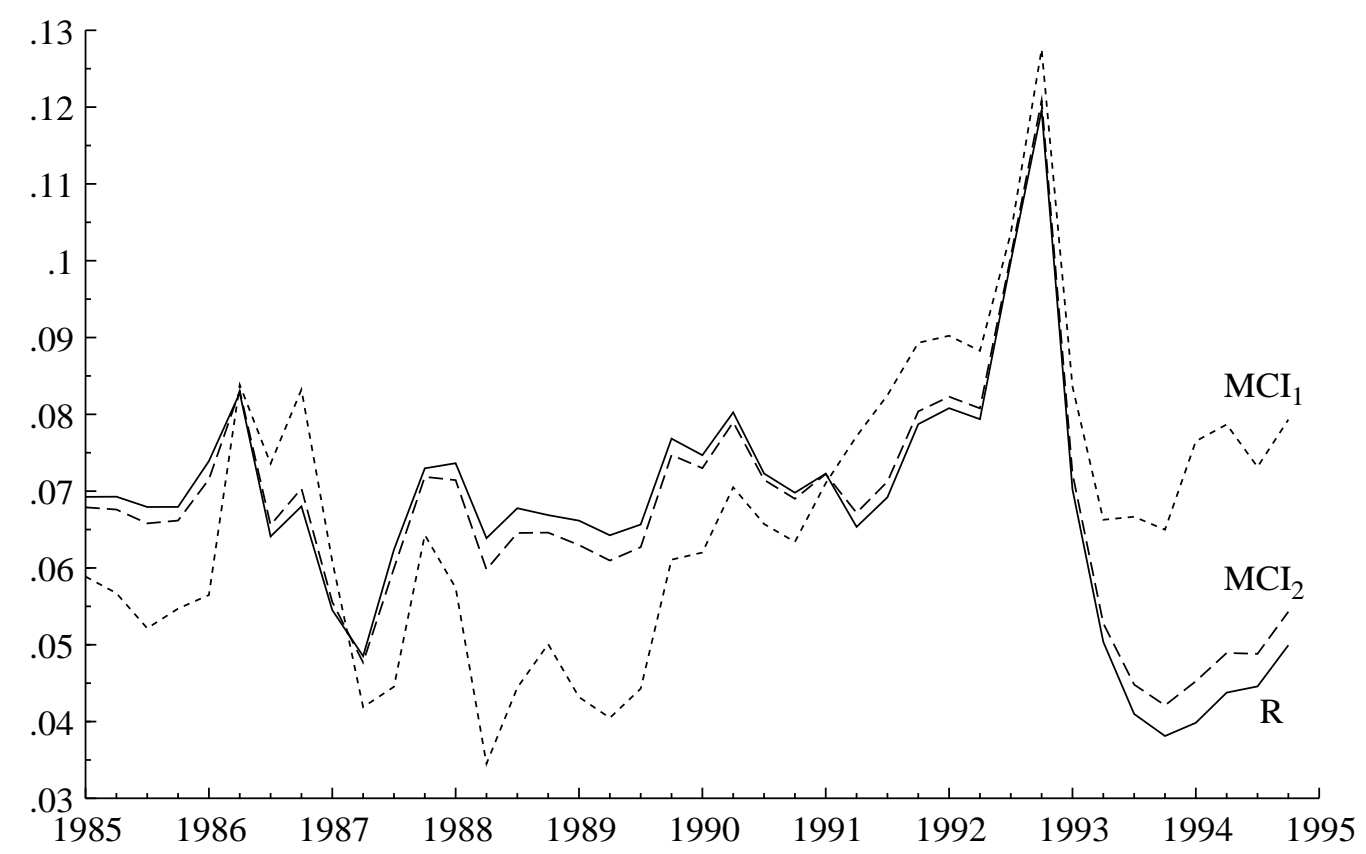

Figure 2: Norwegian MCI indices with original and updated weights $\left(\mathrm{MCI}_{1}\right.$ and $\mathrm{MCI}_{2}$ ), and the interest rate $R$.

in capital and housing markets during the early 1980s. However, the model is also numerically unstable within the deregulated regime. This is reflected by the estimates on the right-hand side of Table 1, for which the sample period has been extended by only four quarters to 1994Q4. Neither the interest rate nor the exchange rate has a statistically significant effect on the output gap, except for a very temporary impact effect from the real exchange rate. The point estimate of the interest rate coefficient is reduced to two-thirds its previous value, and that on the exchange rate to a tenth its previous value.

The minor extension of the estimation period induces large changes in the MCI weights. For instance, in Jore (1994), the eight-quarter interim multiplier for the interest rate is 2.0 times larger than that for the exchange rate. On the extended sample, that ratio is 13.9 . The effect on the calculated MCI itself is clearly visible in Figure 2, which plots the two MCIs $\left(\mathrm{MCI}_{1}\right.$ and $\mathrm{MCI}_{2}$ respectively) and the interest rate $R$, all rescaled to have similar means and ranges. The interest rate and $\mathrm{MCI}_{2}$ are very similar, as follows from the large relative weight of 13.9 , whereas the two MCIs differ notably. From 1988 to $1992, \mathrm{MCI}_{1}$ increases steadily whereas $\mathrm{MCI}_{2}$ remains relatively constant; and in the last two years of the sample the two indices have 
deviated considerably. Even the direction of movement can differ, as in early 1991, so inferences about monetary conditions can be affected by the choice of estimated weights.

\subsection{General Remarks}

Having proceeded through the analytical framework of Section 3 and the empirical descriptions above, some further comments are germane. They concern empirical lag lengths, omitted cointegrating variables, Granger noncausality and invariance, the statistical properties of $e$ and $R$, approximation error due to mis-specification, and estimation uncertainty.

First, omission of a significant error correction term (cointegrating relation) can induce apparent long lags in growth rates of included variables; see Hendry, Pagan, and Sargan (1984) and de Brouwer and Ericsson (1995). The Swedish inflation equation and both Canadian equations have long lags in growth rates and exclude levels relationships. While long lags in growth rates may be required, regardless of cointegration, their possible symptomatic presence should be investigated. With an error correction term, a simpler representation with short lags may be possible, as in de Brouwer and Ericsson (1995). Whether or not long lags in growth rates are required, cointegration changes the interpretation of the coefficients on the growth rates.

Second, and relatedly, all three models omit variables that might be cointegrated with $y$ and $p$, as discussed in Section 3.5. Data on such variables are readily available, and some variables are already included as growth rates: foreign prices in the Swedish and Canadian models, and energy prices in the Canadian model.

Third, none of the three studies tests for Granger noncausality, yet Granger noncausality is critical for interpreting the estimated coefficients as partial derivatives. Equally, in constructing an MCI, the estimated coefficients should be invariant to policy changes and regime switches in sample, yet their empirical constancy remains an open issue. In technical terms, the use of the estimated coefficients for an MCI requires both strong exogeneity and super exogeneity.

Fourth, the MCI in equation (1) can be expressed directly in terms of the levels of $e$ and $R$ :

$$
M C I(v)_{t}=\theta_{v, e} e_{t}+\theta_{v, R} R_{t}
$$

where the constant term $-\left(\theta_{v, e} e_{0}+\theta_{v, R} R_{0}\right)$ is ignored. If the two variables $e$ and $R$ are of different orders of integration, the variable with the higher order of integration will tend to dominate fluctuations in the MCI. For the Canadian MCI, $e$ and $R$ are 
nominal: $R$ might be stationary, but $e$ certainly is not. Because the weight on $e$ is only one-third that on $R$ for Canada, the interest rate dominates some short-term fluctuations in the MCI, such as in late 1992 and the first half of 1994; see the Bank of Canada (1994, pp. 18-19). However, over longer periods, e may well play the larger role. From a policy perspective, constructing an MCI from variables with different orders of integration may result in undesirable properties of the MCI.

Fifth, claims are sometimes made that estimated MCI weights are "roughly" in line with reality and so should provide reasonable policy inferences. For those claims to be credible, the corresponding models would require extensive testing that demonstrated the empirical irrelevance of potential sources of mis-specification such as those described in Section 3. Little such testing has been reported for the three models examined above, and a cursory examination of each suggests that substantive misspecification is likely. To assess the numerical effects of model mis-specification on an MCI, that mis-specification must itself be ascertained.

Sixth, uncertainty in estimation can imply vastly different estimated MCI weights, even if the model is well specified. In Section 4.3, the sensitivity of the Norwegian MCI weights to small changes in the estimation sample reflects estimation uncertainty, at least in part. Neither the interest rate coefficient nor the exchange rate coefficient is particularly significant statistically over either sample. In both Duguay (1994) and Hansson (1993), the interest rate and exchange rate coefficients also have relatively large standard errors compared with their estimated coefficients. For instance, a variation of plus-or-minus one estimated standard error for the exchange rate coefficient in Duguay (1994, p. 50, Table 1, column 7) implies ratios of MCI weights ranging from 1.5 to 11.6 , even while the ratio of actual estimated coefficients is $2 \frac{2}{3}$, essentially the Bank of Canada's selected value of 3. A variation of plus-or-minus two estimated standard errors includes both infinite and negative weights. While formal standard error bands for the ratio of the MCI weights would reflect both coefficients' estimated standard errors and their covariance, this crude calculation illustrates the sensitivity of the empirical MCI weights to estimation uncertainty.

\section{Conclusions}

We have shown that a monetary conditions index is unlikely to be a useful operational policy tool unless numerous assumptions are satisfied by the empirical model from which the MCI is derived. Those assumptions concern dynamics, cointegration, exogeneity, parameter constancy, and omitted variables; and they may well be invalid. Analysis of models for the Canadian, Swedish, and Norwegian MCIs confirms such problems empirically. Several central banks that have been exploring the 
properties of MCIs also acknowledge their theoretical and operational difficulties; see Freedman (1994, pp. 472-474), Mayes and Riches (1996, p. 15), and Reserve Bank of New Zealand (1996) inter alia. While cross-checking and good judgment might avoid substantial policy mistakes arising from such model deficiencies, the implied adjustments would reduce the actual role of an MCI in policy. Thus, the value of existing MCIs for economic policy analysis is doubtful.

While our findings are negative, a constructive approach follows directly. First, the tools and concepts are in place for designing empirically more reliable systems determining output and prices. While the eventual outcome in any empirical research is uncertain ex ante, the approach using these tools has been successful in a number of areas, including consumer expenditure, exchange rates, government deficits, money demand, wages and prices, and trade. Hendry (1987) and Ericsson (1994a) provide selective bibliographies. A well-specified model could be useful in policy analysis, even while an MCI derived from that model would be of questionable value, as discussed in Section 3.6. Second, a univariate measure such as an MCI may be conceptually inappropriate if policy makers are concerned with more than one objective, e.g., low inflation and sustained economic growth. With multiple objectives, understanding the empirical monetary transmission mechanism is particularly important for the conduct of monetary policy. 


\section{Appendix A. The MCI Model for Sweden}

Section 4.2 evaluates the model for the Swedish MCI: namely, (25), (26), and (27). This appendix describes the data for that model and re-estimates and analyzes that model in some detail.

The data are $P$, the Swedish consumer price index (net of indirect taxes and subsidies); $P^{*}$, a weighted average of OECD consumer price indices measured in domestic currency; $R$, a real interest rate for 6-month Swedish Treasury bills (as a fraction at annual rates); $E$, the real exchange rate vis-à-vis the OECD; and $y$, the logarithmic difference between seasonally adjusted GDP and an estimated linear trend in GDP. Further details appear in Hansson (1993) and in Appendix B below.

Table A1 lists the full-sample OLS estimates for (27), the trend model of GDP; Figure 1 plots recursive estimates of the trend coefficient. The estimation sample is $T=92$ [1970Q1-1992Q4].

Table A1: The Auxiliary Model for $G D P_{t}$.

\begin{tabular}{lcc}
\hline \hline Variable & Coefficient & $t$ ratio \\
\hline Constant & 173740. & 149.3 \\
Trend & 725.00 & 33.4 \\
\hline$\hat{\sigma}=5536.3$ & $\mathrm{R}^{2}=0.93$ & $D W=0.21$ \\
\hline \hline
\end{tabular}

The Durbin-Watson statistic $D W$ indicates the presence of strong positive autocorrelation in the residuals, so the reported (OLS) $t$ ratios are likely to be biased upward.

In Hansson (1993), the model (25)-(26) is estimated by a "three step method", which is subsystem three-stage least squares (3SLS). The variables $y, \Delta p$, and $\Delta p^{*}$ are treated as endogenous, but only equations for $y$ and $\Delta p$ are estimated. Additional instruments are lagged changes in the "output gap" $\left(\Delta y_{t-i}\right)$, further lags in foreign inflation $\left(\Delta p_{t-i}^{*}\right)$, a constant, and a trend. For these instruments to be valid, they must be significant determinants in the reduced form for the unmodeled endogenous variable $\Delta p_{t}^{*}$. To investigate this auxiliary assumption, we estimate (25)-(26) augmented by the reduced-form equation for $\Delta p_{t}^{*}$, where $\Delta p_{t}^{*}$ depends on $y_{t-1}, \ldots, y_{t-5}$, $\Delta p_{t-1}, \ldots, \Delta p_{t-4}, \Delta p_{t-1}^{*}, \ldots, \Delta p_{t-13}^{*}, e_{t-1}, R_{t-1}$, a constant, and a trend. Estimates for (25)-(26) appear in Table A2. The estimation sample is $T=78$ [1973Q3-1992Q4]. The estimates in Table A2 are obtained by Full Information Maximum Likelihood (FIML), which differ slightly from the 3SLS estimates in Hansson (1993). With FIML, inflation and the real exchange rate have stronger effects in the output equation, whereas the estimated coefficients in the price equation are almost identical to those in Hansson (1993), although generally with somewhat lower significance levels. 
Table A2: The Output and Inflation Equations.

\begin{tabular}{lrrrr}
\hline \hline Variable & \multicolumn{2}{c}{ Output Equation } & \multicolumn{2}{c}{ Inflation Equation } \\
\cline { 2 - 5 } & Coefficient & $t$ ratio & Coefficient & $t$ ratio \\
\hline$y_{t}$ & -1 & - & 0.124 & 2.4 \\
$y_{t-1}$ & 0.467 & 3.8 & & \\
$y_{t-2}$ & 0.469 & 3.8 & & \\
$\Delta p_{t}$ & -0.374 & -3.0 & -1 & - \\
$\Delta p_{t-1}$ & & & 0.100 & - \\
$\Delta p_{t-2}$ & & & 0.043 & 0.4 \\
$\Delta p_{t-3}$ & & & 0.105 & 0.9 \\
$\Delta p_{t-4}$ & & & 0.309 & 2.8 \\
$R_{t-1}$ & -0.154 & -2.5 & & \\
$e_{t-1}$ & 0.076 & 3.1 & & \\
$\Delta p_{t}^{*}$ & & & 0.132 & 2.0 \\
$\Delta p_{t-1}^{*}$ & & & 0.029 & 0.6 \\
$\Delta p_{t-2}^{*}$ & & & 0.093 & 2.1 \\
$\Delta p_{t-3}^{*}$ & & & 0.044 & 0.9 \\
$\Delta p_{t-4}^{*}$ & & & 0.020 & 0.4 \\
$\Delta p_{t-5}^{*}$ & & & -0.071 & -1.5 \\
$\Delta p_{t-6}^{*}$ & & & 0.015 & 0.3 \\
$\Delta p_{t-7}^{*}$ & & & 0.034 & 0.7 \\
$\Delta p_{t-8}^{*}$ & & & -0.023 & -0.5 \\
$\Delta p_{t-9}^{*}$ & & & 0.022 & 0.5 \\
$\Delta p_{t-10}^{*}$ & & & 0.149 & 3.4 \\
\hline$\hat{\sigma}$ & & & & $0.934 \%$ \\
\hline \hline
\end{tabular}

The model in Hansson (1993) restricts the sum of coefficients on $\Delta p_{t-1}, \ldots, \Delta p_{t-4}$, $\Delta p_{t}^{*}, \ldots, \Delta p_{t-10}^{*}$ in (26) to equal unity. This restriction is also imposed in the estimates reported in Table A2, with the coefficient on $\Delta p_{t-1}$ being derived from the restriction. The unit restriction by itself is not rejected: $\chi^{2}(1)=0.54$ [0.46], where the $p$-value is in square brackets $[\cdot]$. However, the estimated system is rejected against its unrestricted reduced form: $\chi^{2}(32)=48.1$ [0.034], invalidating the test of the unit restriction. Equally, the unit restriction need not hold once an error correction is introduced, as in de Brouwer and Ericsson (1995) and Ericsson (1994b).

The system for $y, \Delta p$, and $\Delta p^{*}$ was re-estimated by FIML rather than 3SLS because FIML has been implemented as a recursive algorithm to generate sequential tests of parameter constancy. Figure A1 plots the recursive one-step residuals and their standard errors for each equation, and the one-step ahead Chow statistics for the 

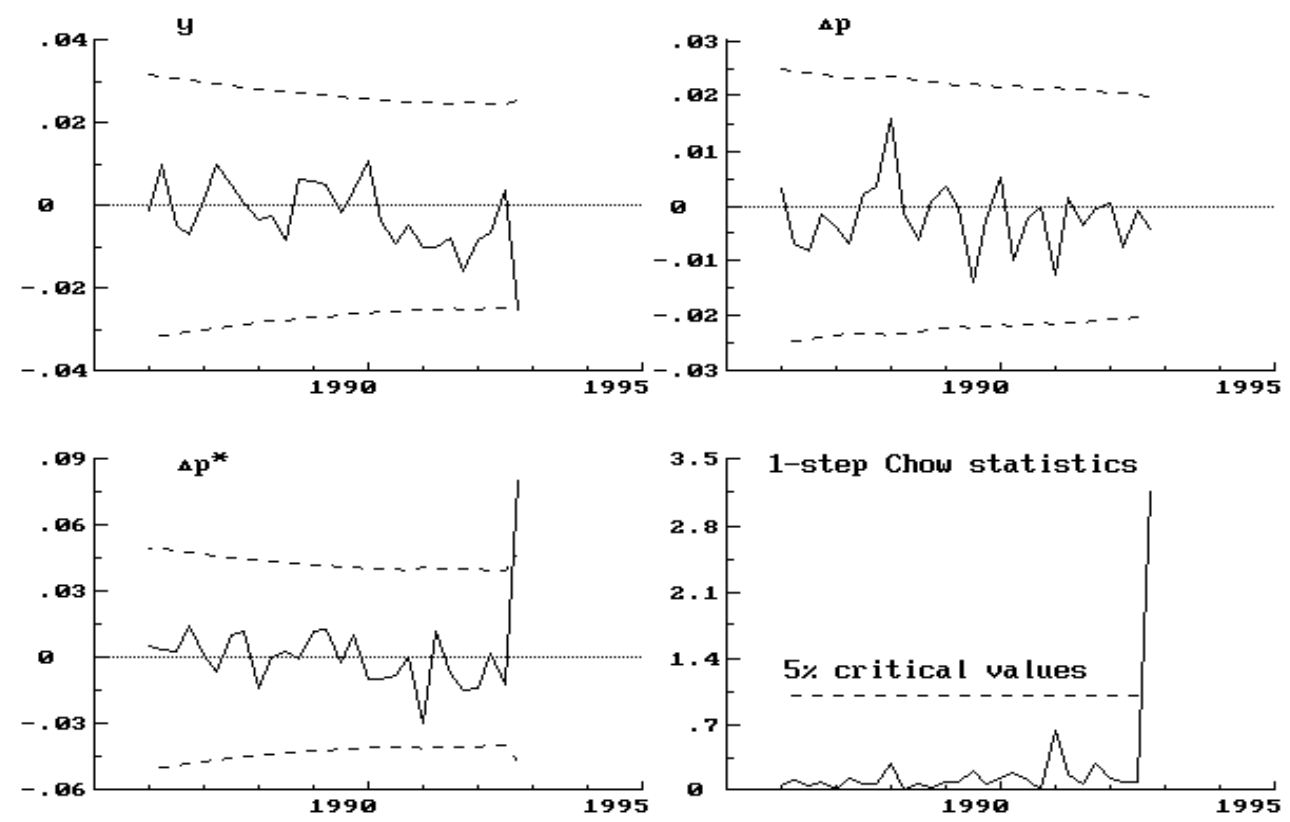

Figure A1: One-step residuals $(-)$ with \pm 2 times the corresponding equation standard errors $(--)$ for the equations for $y, \Delta p$, and $\Delta p^{*}$ in the Swedish MCI model, and the one-step model Chow statistics.

trivariate system as a whole. Notably, the reduced form for $\Delta p^{*}$ exhibits parameter nonconstancy at the very end of the estimation sample (late 1992). This nonconstancy per se does not impinge directly on the coefficients used for calculating the MCI weights. However, the nonconstancy may reflect changes in Granger causality or the presence of significant omitted variables, either of which would bear on the calculation of the MCI.

Finally, consider the fit of the system (25)-(26) augmented by the reduced form equation for $\Delta p_{t}^{*}$. The equation standard errors of the three equations are $1.267 \%$, $0.934 \%$, and $2.546 \%$, respectively. By contrast, the standard deviations of $y_{t}\left[\Delta y_{t}\right]$, $\Delta p_{t}$, and $\Delta p_{t}^{*}$ are $2.708 \%$ [1.252\%], $1.051 \%$, and $2.938 \%$. That is, a random walk model for $y_{t}$ fits slightly better than (25); and (26) and the reduced form equation for $\Delta p_{t}^{*}$ offer only marginal improvement over models for $\Delta p_{t}$ and $\Delta p_{t}^{*}$ as white noise. That said, other variables may play an important role in determining $y_{t}, \Delta p_{t}$, and $\Delta p_{t}^{*}$, as may the included variables at other lags or in other transformations. 


\section{Appendix B. Data Definitions and Sources}

This appendix lists the data definitions and their sources. This information is organized in two subsections, one for each of the two MCI models that has been reestimated. Bengt Hannson of Sveriges Riksbank and Anne Sofie Jore of Norges Bank have kindly made available the data for their models in Hansson (1993) and Jore (1994), so this appendix primarily serves to document those data.

All data are quarterly. Seasonally adjusted series are denoted by SA, those not seasonally adjusted by NSA. Series names are provided in Swedish or Norwegian, with English translations in brackets. Sources generally indicate where the most recent values of the series could be obtained.

\section{B.1 Sweden}

- $E$ : Real valutakurs. [Real exchange rate.] Constructed as the ratio of foreign prices (i.e., bilateral exchange rates times foreign consumer prices, weighted by OECD overall weights for Sweden) to domestic consumer prices (net of indirect taxes and subsidies).

Units: $1970 \mathrm{Q} 1=1.00(1980 \approx 1.05)$.

Source: Sveriges Riksbank.

- GDP: Bruttonationalprodukt (BNP). [Gross Domestic Product.]

Units: Million SEK, 1985 prices, quarterly rate, NSA. SA data were used in Hansson (1993) and were obtained by seasonally adjusting the NSA data with $\mathrm{X} 11$.

Source: Allmän månadsstatistik [Monthly Digest of Swedish Statistics], Statistiska Centralbyrån [Statistics Sweden], 1994:1, Table P, column 9 (NSA data). Sveriges Riksbank (SA data).

- $P$ : Nettoprisindex. [Consumer price index, net of indirect taxes and subsidies.] Units: $1980=100$, quarterly average of monthly data, NSA. In Hansson (1993), a different base year is used, such that $1980 \approx 340$.

Source: Allmän månadsstatistik [Monthly Digest of Swedish Statistics], Statistiska Centralbyrån [Statistics Sweden], 1994:1, Table J, column 11.

- $R N$ : Nominell sexmånadersränta på statsskuldväxlar. [Nominal interest rate on 6-month Swedish Treasury Bills.]

Units: Percent per annum, quarterly average of monthly averages, NSA. 
Source: Penning- och valutapolitik [Quarterly Review], Sveriges Riksbank, 1993:1, Table 16.

Several transformations of the data are required for the model estimated in Hansson (1993): the output gap $y_{t}$, calculated as $\ln \left(G D P_{t} / \widehat{G D P_{t}}\right)$, where $\widehat{G D P_{t}}$ is the fitted value from the trend regression (27) reported in Table A1; a real interest rate $R_{t}$, calculated as $R N_{t}-100 \cdot \Delta_{4} \ln \left(P_{t}\right)$; and a trade-weighted foreign consumer price index $P_{t}^{*}$, calculated as $E_{t} \cdot P_{t}$, noting that $E_{t}$ is the real exchange rate. Results in Table A2 are reported for $R$ as a fraction, so that its coefficient is more directly comparable to the one on $e$.

\section{B.2 Norway}

All series have been extended, and some have been updated and/or redefined, relative to those used in Jore (1994). The text below indicates the ways in which these changes have occurred. The data revisions and redefinitions have little effect on the empirical estimates for Jore's model, whereas the extension of the sample period has substantial effects. For some series, numbers are also given for TROLL8, a Norges Bank databank of economic time series.

- EN: Nominell effektiv kronekurs. [Nominal trade-weighted krone effective exchange rate.] The exchange rate of the Norwegian krone against a weighted average of currencies of Norway's sixteen main trading partners. The weights are annually updated OECD trade weights. In Jore (1994), the weights are based on IMF trade weights. For a discussion of the differences between the two indices, see Penger og kreditt, Norges Bank, 1995/3, p. 167 [Economic Bulletin, Norges Bank, 1995/3, p. 290].

Units: December $1994=103.68$ (renormalized in our data such that $1991=$ 1.00), Norwegian krone per unit of foreign currency, NSA.

Source: Penger og kreditt [Economic Bulletin], Norges Bank, 1995/4, Table 39 (TROLL8, Series M9350812). For Jore (1994), see TROLL8, Series M9350012.

- GDP: Bruttonasjonalprodukt (BNP) for Fastlands-Norge. [Gross Domestic Product for mainland Norway.] Total value added, less oil and gas production and shipping. Data for the extended sample differ from those in Jore (1994) because of revisions to the quarterly national accounts.

Units: Million NOK, 1991 prices, at base value, quarterly rate, NSA. SA data were used in Jore (1994). The SA data were obtained by seasonally adjusting 
the NSA data with X11 for the sample 1966Q1-1993Q4 (for Jore (1994)) and for the sample 1966Q1-1994Q4 (for the extended sample).

Source: Økonomiske analyser, Statistics Norway, 2/95, Table A4 (NSA data). For Jore (1994), see Økonomiske analyser, Statistics Norway, 1/94, Table A4 (NSA data).

- $P$ : Konsumprisindeks. [Consumer price index.]

Units: $1985=100$ for 1966-1992 and $1979=100$ for 1993-1994 (both renormalized in our data such that $1991=1.00)$, quarterly average of monthly data, NSA.

Source: Historisk statistikk [Historical Statistics] 1994, Statistics Norway, Table 12.4; and Statistisk månedshefte [Monthly Bulletin of Statistics], Statistics Norway, 1/95, Table 15 .

- $P^{*}$ : Konsumprisindeks i markedsland. [Consumer price index for Norway's main trading partners.] Trade-weighted average of consumer price indices for Norway's main trading partners, measured in foreign currency. The weights correspond to the weights for the nominal effective exchange rate $E N$ listed above.

Units: $1990=100$ (renormalized in our data such that $1991=1.00$ ), quarterly average of monthly data.

Source: Norges Bank, TROLL8, Series M4690512. For Jore (1994), see TROLL8, Series M4690312.

- $R N$ : Tremåneders eurokronerente. [Three-month Eurokrone interest rate.] Norwegian Interbank Offered Rate (NIBOR), constructed on the basis of currency swaps.

Units: Fraction, quarterly average of monthly data, NSA.

Source: Penger og kreditt [Economic Bulletin], Norges Bank, 1995/4, Table 27 (TROLL8, Series M901605a).

Several transformations of the data are required for the model estimated in Jore (1994): the output gap $y_{t}$, calculated as the deviation of $\ln \left(G D P_{t}\right)$ from a HodrickPrescott trend of $\ln \left(G D P_{t}\right)$, where the HP smoothing parameter $\lambda$ is $\lambda=100000$ and the whole sample period is used, starting in 1966Q1; a real interest rate $R_{t}$, calculated as $R N_{t}-\left(P_{t}-P_{t-4}\right) / P_{t-4}$; and a real exchange rate $E_{t}$, calculated as $E N_{t} \cdot P_{t}^{*} / P_{t}$. This definition of $E$ equals the inverse of that in Jore (1994). 


\section{References}

Bank of Canada (1994). "Monetary Conditions — Les Conditions Monétaires", Bank of Canada Review - Revue de la Banque du Canada, 1994 (Autumn), 18-20.

Bank of Canada (1995). Monetary Policy Report, 1995 (May). Bank of Canada, Ottawa, Canada.

de Brouwer, G., and Ericsson, N. R. (1995). "Modelling Inflation in Australia", International Finance Discussion Paper No. 530, Board of Governors of the Federal Reserve System, Washington, D.C., November.

Chote, R. (1996). "IMF Urges Rate Cut by Germany", Financial Times, (April 18), 1.

Chow, G. C. (1960). "Tests of Equality between Sets of Coefficients in Two Linear Regressions", Econometrica, 28(3), 591-605.

Davies, G., and Simpson, J. (1996). "Summary", The Internnational Economics Analyst (Goldman Sachs), 11 (7/8), iii-xviii.

Doornik, J. A., and Hendry, D. F. (1994). PcGive Professional 8.0: An Interactive Econometric Modelling System. International Thomson Publishing, London.

Duguay, P. (1994). "Empirical Evidence on the Strength of the Monetary Transmission Mechanism in Canada: An Aggregate Approach", Journal of Monetary Economics, 33(1), 39-61.

Engle, R. F., and Granger, C. W. J. (1987). "Co-integration and Error Correction: Representation, Estimation, and Testing", Econometrica, 55(2), 251-276.

Engle, R. F., Hendry, D. F., and Richard, J.-F. (1983). "Exogeneity", Econometrica, $51(2), 277-304$.

Ericsson, N. R. (1994a). "Hendry Approach on Money Demand Equations", memo, Division of International Finance, Board of Governors of the Federal Reserve System, Washington, D.C., September.

Ericsson, N. R. (1994b). "Models of the U.S. CPI", memo, Division of International Finance, Board of Governors of the Federal Reserve System, Washington, D.C., July.

Ericsson, N. R., Campos, J., and Tran, H.-A. (1990). "PC-GIVE and David Hendry's Econometric Methodology", Revista de Econometria, 10(1), 7-117. 
Franz, W., and Gordon, R. J. (1993). "German and American Wage and Price Dynamics: Differences and Common Themes", European Economic Review, 37(4), 719-762. With discussion.

Freedman, C. (1994). "The Use of Indicators and of the Monetary Conditions Index in Canada", In Baliño, T. J. T., and Cottarelli, C. (eds.), Frameworks for Monetary Stability: Policy Issues and Country Experiences, Chapter 18, 458476. International Monetary Fund, Washington, D.C.

Granger, C. W. J. (1969). "Investigating Causal Relations by Econometric Models and Cross-spectral Methods", Econometrica, 37(3), 424-438.

Hansson, B. (1993). "A Structural Model”, In Franzén, T., Andersson, K., Alexius, A., Berg, C., Hansson, B., Nilsson, C., and Nilsson, J. (eds.), Monetary Policy Indicators, Chapter 5, 55-64. Sveriges Riksbank, Stockholm, Sweden.

Hansson, B., and Lindberg, H. (1994). "Monetary Conditions Index - A Monetary Policy Indicator", Quarterly Review (Sveriges Riksbank — Swedish Central Bank), 1994(3), 12-17.

Hendry, D. F. (1987). "Econometric Methodology: A Personal Perspective", In Bewley, T. F. (ed.), Advances in Econometrics: Fifth World Congress, Chapter 10, Volume 2, 29-48. Cambridge University Press, Cambridge.

Hendry, D. F., and Doornik, J. A. (1994). "Modelling Linear Dynamic Econometric Systems", Scottish Journal of Political Economy, 41(1), 1-33.

Hendry, D. F., and Mizon, G. E. (1993). "Evaluating Dynamic Econometric Models by Encompassing the VAR", In Phillips, P. C. B. (ed.), Models, Methods, and Applications of Econometrics: Essays in Honor of A. R. Bergstrom, Chapter 18, 272-300. Basil Blackwell, Cambridge, Massachusetts.

Hendry, D. F., Pagan, A. R., and Sargan, J. D. (1984). "Dynamic Specification", In Griliches, Z., and Intriligator, M. D. (eds.), Handbook of Econometrics, Chapter 18, Volume 2, 1023-1100. North-Holland, Amsterdam.

International Monetary Fund (1996). World Economic Outlook: May 1996. International Monetary Fund, Washington, D.C.

Johansen, S. (1991). "Estimation and Hypothesis Testing of Cointegration Vectors in Gaussian Vector Autoregressive Models", Econometrica, 59(6), 1551-1580. 
Jore, A. S. (1994). "Beregning av en Indikator for Pengepolitikken" (Calculation of an Indicator for Monetary Policy), Penger og Kreditt, 94 (2), 100-105.

Juselius, K. (1992). "Domestic and Foreign Effects on Prices in an Open Economy: The Case of Denmark", Journal of Policy Modeling, 14 (4), 401-428.

Leiderman, L., and Svensson, L. E. O. (eds.) (1995). Inflation Targets. Centre for Economic Policy Research, London.

Mayes, D. G., and Riches, B. (1996). "The Effectiveness of Monetary Policy in New Zealand", Reserve Bank Bulletin (Reserve Bank of New Zealand), 59(1), 5-19.

Reserve Bank of New Zealand (1996). "Summary Indicators of Monetary Conditions", Reserve Bank Bulletin (Reserve Bank of New Zealand), 59(3), 223-228.

Suttle, P. (1996). "Monetary Conditions Worldwide", World Financial Markets (JP Morgan), (March 29), 26. 